\title{
How early-career researchers are shaping elife
}

\section{Journals can benefit from listening to graduate students, postdocs and newly-independent group leaders.}

\author{
MARK PATTERSON AND RANDY SCHEKMAN
}

$\mathrm{B}$ efore elife published its first article, there was already strong agreement within the initiative that the journal had to appeal to early-career researchers, as well as established scientists. Towards this end we introduced a number of measures that, we hoped, would encourage graduate students, postdocs and new group leaders to submit their work to the journal (Schekman et al., 2013). Now, more than five years on, our relationship with earlycareer researchers has evolved considerably as they have become more involved in the governance of elife and discussions about the future of the journal and the elife initiative more broadly.

The first concrete step that elife took in this direction was to recruit an Early-Career Advisory Group (ECAG) in 2014. Inspired by perspectives from researchers whose opinions resonated strongly with elife's mission, a team of 14 graduate students, postdocs and newly-independent group leaders was assembled. This group has provided insight, ideas and constructive criticism of eLife policies and practices and, as discussed below, has helped to refine and launch several initiatives.

One of the most important outcomes from the ECAG discussions has been the recruitment of a pool of early-career reviewers. It is common practice for busy group leaders to ask their more senior PhD students and postdoctoral fellows to help with peer review, but in too many cases these contributions go unacknowledged. Nevertheless, such experience can help an earlycareer researcher gain the confidence and judgment to participate in peer review in their own right. Building on this practice and after discussions with the ECAG, we asked our Board of Reviewing Editors to nominate early-career colleagues who they felt were ready to act as independent peer reviewers. We have now amassed a group of more than 250 early-career reviewers; around 100 have peer-reviewed elife submissions, and have also benefited from the open consultation that takes place between reviewers in the elife process.

The involvement of the early-career community in elife's publishing work is only set to increase as we expand the early-career reviewer pool and find better ways to bring these individuals to the attention of editors when they are looking for referees. In addition, several earlycareer reviewers have recently become Reviewing Editors for the journal. Another benefit of the early-career reviewer pool is that it is more balanced with respect to gender and geography than the existing editorial community. As well as helping to identify highly competent editors and reviewers, we therefore hope that the reviewer pool will lead to greater diversity in all aspects of our publishing.

We have also appointed an early-career researcher to the eLife Board of Directors. One of the important functions of the Board of a non-profit organization like elife is to provide oversight of our strategic direction, and to ensure that we stay true to our mission. Earlycareer researchers are a critical constituency in elife's mission, and it therefore makes complete sense to have that constituency represented at the highest levels of governance in our organization. 
We have now amassed a group of more than 250 early-career reviewers review. The editors felt that they were not serving the interests of beginning investigators well in this way, and that it was better to assess all initial submissions by the same standards.

Other initiatives have been built upon or launched. The ECAG has helped to refine our travel grant program and has introduced a series of webinars on topics of interest to the earlycareer community. All of these webinars have been recorded and are building into a valuable resource. Early-career researchers and issues of concern to them are also regularly featured on the Community page, and in interviews, podcasts and articles in the Magazine section of elife.

eLife's mission is about the future of science. Whether we are talking about innovations in technology to support greater reproducibility, editorial policies that set the standards for elife research articles, or the long-term financial sustainability of elife, early-career perspectives are part of the conversation. Our work at elife has been enriched by these perspectives, and no doubt so would many other initiatives aimed at improving the culture and communication of research. new initiatives aimed at improving the operation of scientific publishing.

As elife has grown and become established as a major publication in the life and biomedical sciences, some of the initial approaches that we introduced to support early-career researchers have been adjusted. For example, senior editors would often write letters of support for earlycareer eLife authors to help with job and funding applications, but such supporting letters are now requested only infrequently. Another policy was to peer review more articles from newlyindependent investigators so that these authors could benefit from more detailed feedback. Although a higher proportion of early-career articles were invited for peer review, a higher proportion were also then rejected after peer
Mark Patterson is the Executive Director of eLife m.patterson@elifesciences.org (iD) https://orcid.org/0000-0001-7237-0797

Randy Schekman is the Editor-in-Chief of eLife (iD) https://orcid.org/0000-0001-8615-6409

Competing interests: Randy Schekman: Receives funding from the Howard Hughes Medical Institute. The other author declares that no competing interests exist.

Published 27 March 2018

\section{References}

Schekman R, Watt FM, Weigel D. 2013. eLife and early career researchers. eLife 2:e01633. DOl: https:// doi.org/10.7554/eLife.01633, PMID: 24156031 